\title{
Compound C prevents Hypoxia-Inducible Factor- $1 \alpha$ protein stabilization by regulating the cellular oxygen availability via interaction with Mitochondrial Complex I
}

Yee Liu Chua and Thilo Hagen*

\begin{abstract}
The transcription factor Hypoxia-Inducible Factor-1 $\alpha$ is a master regulator of the cellular response to low oxygen concentration. Compound C, an inhibitor of AMP-activated kinase, has been reported to inhibit hypoxia dependent Hypoxia-Inducible Factor-1 $\alpha$ activation via a mechanism that is independent of AMP-activated kinase but dependent on its interaction with the mitochondrial electron transport chain. The objective of this study is to characterize the interaction of Compound $\mathrm{C}$ with the mitochondrial electron transport chain and to determine the mechanism through which the drug influences the stability of the Hypoxia-Inducible Factor-1 $\alpha$ protein.

We found that Compound $C$ functions as an inhibitor of complex I of the mitochondrial electron transport chain as demonstrated by its effect on mitochondrial respiration. It also prevents hypoxia-induced Hypoxia-Inducible Factor- $1 \alpha$ stabilization in a dose dependent manner. In addition, Compound $C$ does not have significant effects on reactive oxygen species production from complex I via both forward and reverse electron flux.

This study provides evidence that similar to other mitochondrial electron transport chain inhibitors, Compound $\mathrm{C}$ regulates Hypoxia-Inducible Factor- $1 \alpha$ stability by controlling the cellular oxygen concentration.
\end{abstract}

\section{Findings}

Compound $\mathrm{C}$ has been reported to inhibit hypoxia dependent Hypoxia-Inducible Factor- $1 \alpha$ (HIF-1 $\alpha$ ) stabilization by interacting with the mitochondrial electron transport chain (ETC) and suppressing mitochondria generated reactive oxygen species [1]. This finding coincides with the hypothesis that increased reactive oxygen species (ROS) released from mitochondrial complex III during hypoxia stabilize HIF-1 $\alpha$ [2-4]. However our recent findings showed that the mitochondrial electron transport chain controls the stability of HIF-1 $\alpha$ during hypoxia independently of reactive oxygen species production [5]. We therefore studied the mechanism through which Compound C interacts with the ETC in detail.

\footnotetext{
* Correspondence: bchth@nus.edu.sg

Department of Biochemistry, Yong Loo Lin School of Medicine, National University of Singapore, 117597 Singapore
}

Effect of Compound C on hypoxia-induced HIF- $1 \alpha$ protein stabilization

We first determined the effect of Compound $\mathrm{C}$ on hypoxia-induced HIF-1 $\alpha$ protein accumulation. 143B cells from ATCC (ATCC number: CRL-8303) were incubated at either $21 \%$ or $1 \% \mathrm{O}_{2}$ for 4 hours in the presence of Compound $\mathrm{C}(20 \mu \mathrm{M}, 40 \mu \mathrm{M}$ and $80 \mu \mathrm{M})$ and then analyzed using immunoblotting. At $1 \% \mathrm{O}_{2}$, HIF- $1 \alpha$ protein is stabilized in untreated control cells. This is due to inhibition of prolyl hydroxylases which in the presence of oxygen hydroxylate HIF-1 $\alpha$ and therefore target it for proteasomal degradation. The treatment with increasing concentrations of Compound $\mathrm{C}$ at $1 \% \mathrm{O}_{2}$ caused a dose dependent decrease in HIF- $1 \alpha$ protein accumulation (Figure 1A). The result confirms that Compound $\mathrm{C}$ inhibits hypoxia induced HIF-1 $\alpha$ protein stabilization [1].

( 


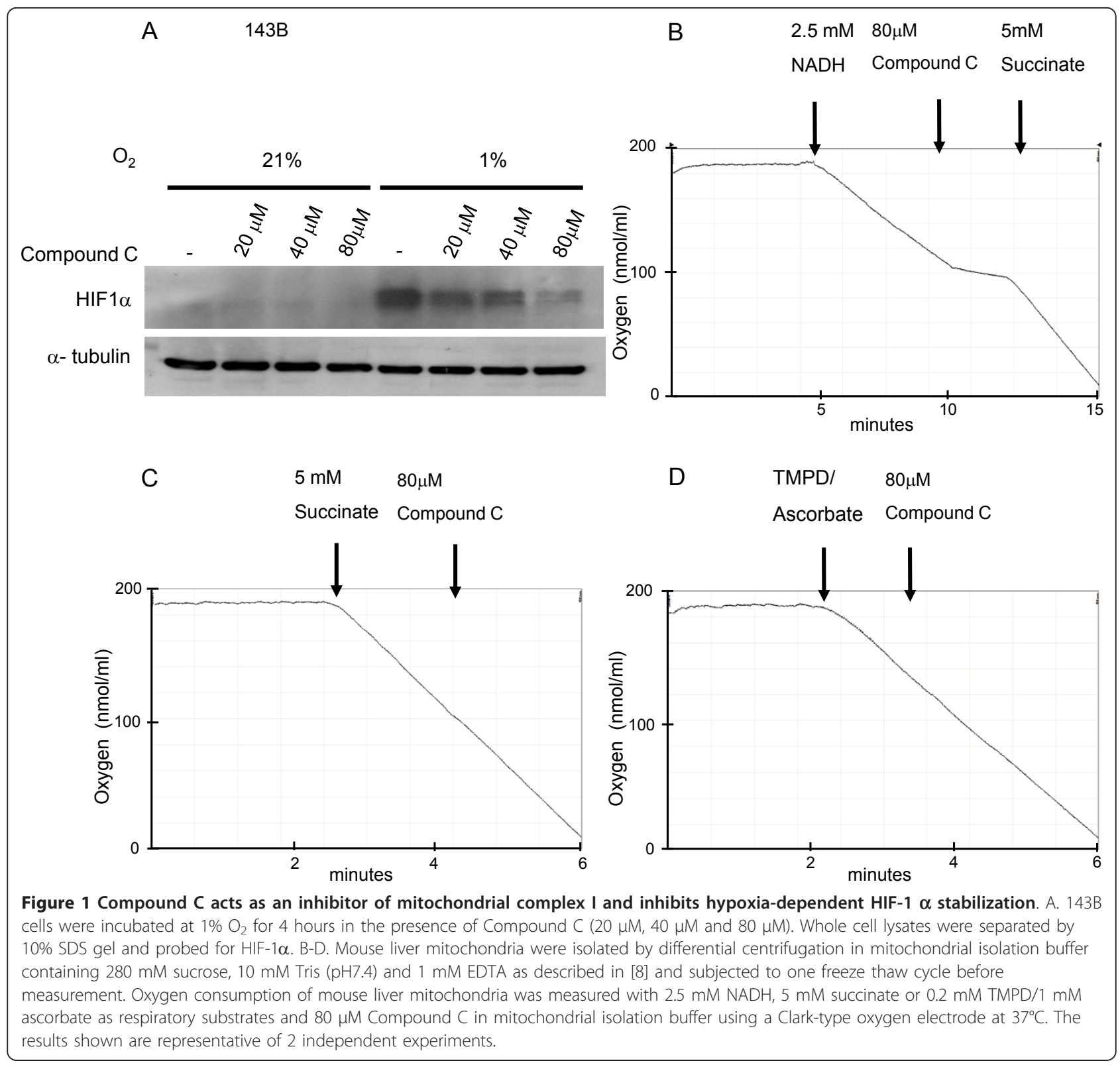

Effect of Compound $\mathrm{C}$ on mitochondrial respiration

To study the effects of Compound $\mathrm{C}$ on the mitochondrial ETC, we measured the oxygen consumption in 0.5 $\mathrm{mg}$ of mouse liver mitochondria with a Clarke-type oxygen electrode. Mitochondria were subjected to one freeze-thaw cycle before the measurement and NADH $(2.5 \mathrm{mM})$ was used as the respiratory substrate for complex I. Treatment of mitochondria with $80 \mu \mathrm{M}$ Compound $\mathrm{C}$ inhibited respiration by $74.5 \%$. Oxygen consumption resumed when the respiratory substrate for complex II, succinate $(5 \mathrm{mM})$ was added, as illustrated in Figure 1B. These results suggest that Compound $\mathrm{C}$ is an inhibitor of complex I and does not inhibit downstream complexes. To determine if
Compound C interacts with complex II, III or IV, Compound $\mathrm{C}$ was added to mitochondria respiring on succinate. Compound $\mathrm{C}$ did not inhibit succinate dependent oxygen consumption (Figure 1C) and therefore does not interact with complex II, III or IV. To directly test if Compound $\mathrm{C}$ is an inhibitor of complex IV, $0.2 \mathrm{mM}$ 2,2,4-trimethyl-1,3-pentanediol (TMPD)/1 mM ascorbate was added. TMPD is an artificial electron donor that transfers electrons from ascorbate to complex IV via cytochrome $c$. Compound $C$ had no effect on the oxygen consumption when TMPD/ascorbate was used as the respiratory substrate (Figure 1D). These results imply that Compound $\mathrm{C}$ inhibits mitochondrial respiration through its interaction with complex I. 


\section{Effect of Compound C on ROS production from isolated mouse liver mitochondria}

Mitochondrial respiratory complex I is one of the two main sites that are capable of producing ROS within the ETC [6]. ROS from complex I can be derived from both forward and reverse electron flux. To determine whether ROS are produced from either of the electron fluxes in the presence of Compound $\mathrm{C}$, the rate of hydrogen peroxide $\left(\mathrm{H}_{2} \mathrm{O}_{2}\right)$ production was measured. In this assay, 0.1 $\mathrm{mg} / \mathrm{ml}$ of isolated mouse liver mitochondria were added to $2 \mathrm{ml}$ of reaction buffer (containing $125 \mathrm{mM} \mathrm{KCl}, 2$ $\mathrm{mM} \mathrm{KH} \mathrm{PO}_{4}, 1 \mathrm{mM} \mathrm{MgCl}$, $20 \mathrm{mM}$ HEPES, $0.1 \mathrm{mM}$
EGTA pH7.4) in the presence of $0.1 \mathrm{mM}$ homovanillic acid, $0.5 \mu \mathrm{M}$ horseradish peroxidase and different respiratory substrates at $37^{\circ} \mathrm{C}$. The rate of $\mathrm{H}_{2} \mathrm{O}_{2}$ production was measured fluorometrically at Ex/Em 312/420 nm using a Perkin Elmer LS-55 fluorescence spectrometer. In the presence of glutamate and malate, addition of the well-established complex I inhibitor rotenone resulted in a moderate increase in the $\mathrm{H}_{2} \mathrm{O}_{2}$ production from complex I via the forward electron flux (Figure 2A). As expected, $\mathrm{H}_{2} \mathrm{O}_{2}$ production via reverse electron flux was inhibited by rotenone when the mitochondria were energized with succinate (Figure 2B). Addition of
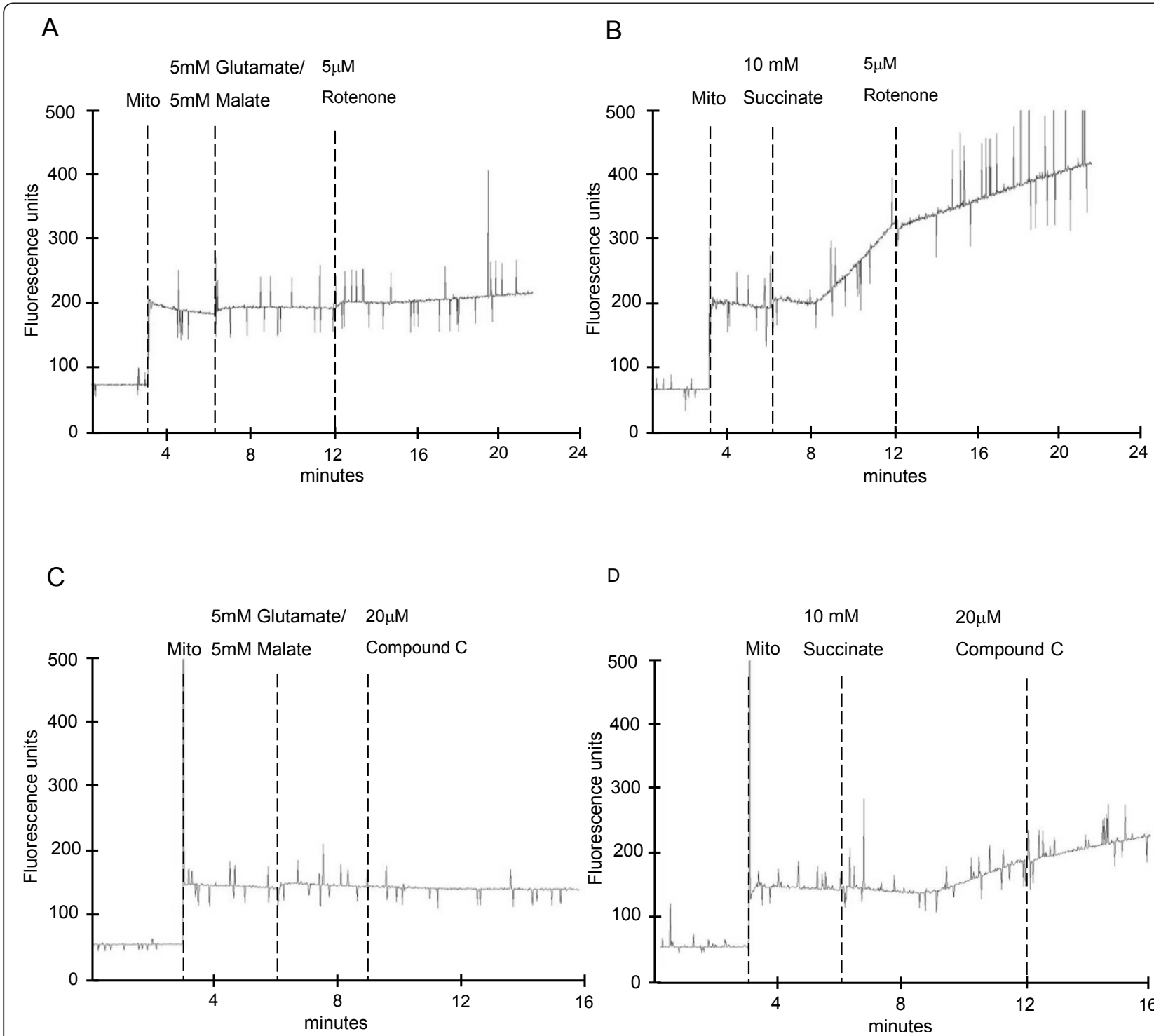

D

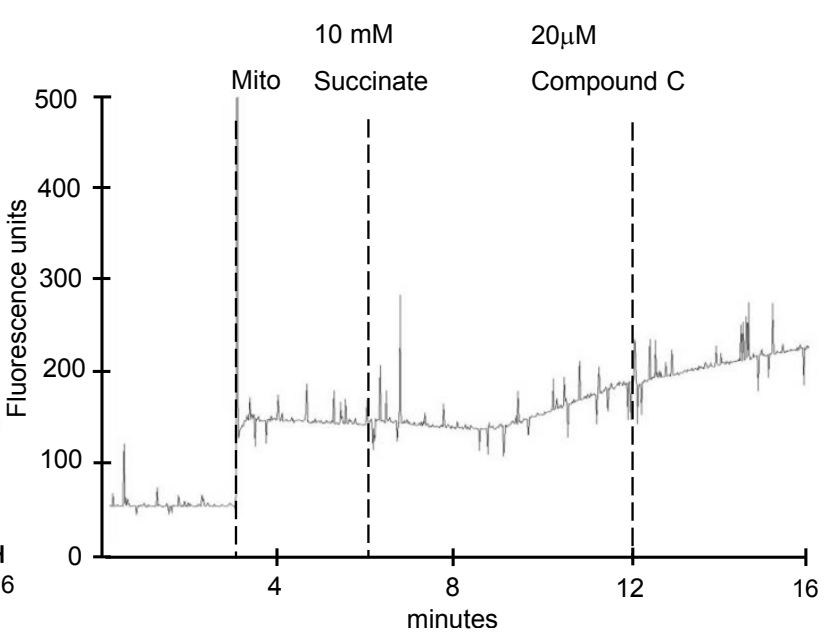

Figure 2 Compound C does not increase hydrogen peroxide production from both forward and reverse electron flux of complex I. 0.1 $\mathrm{mg} / \mathrm{ml}$ of isolated mouse liver mitochondria were incubated in reaction buffer with either $5 \mathrm{mM}$ glutamate/5 mM malate or $10 \mathrm{mM}$ succinate as respiratory substrates or inhibitors $(5 \mu \mathrm{M}$ rotenone and $20 \mu \mathrm{M}$ Compound $\mathrm{C})$ at $37^{\circ} \mathrm{C}$. Hydrogen peroxide production was assessed by homovanillic acid/horseradish peroxidase. Mitochondria, substrates and inhibitors were sequentially added as shown in the figure. The results shown are representative of 2 independent experiments. 
Compound $\mathrm{C}$ was without effect on $\mathrm{H}_{2} \mathrm{O}_{2}$ production via the forward electron flux (Figure $2 \mathrm{C}$ ) $\mathrm{H}_{2} \mathrm{O}_{2}$ production via the reverse electron flux was also not increased but showed a slight decrease (Figure 2D).

To measure the cellular $\mathrm{H}_{2} \mathrm{O}_{2}$ and superoxide production in mammalian cells, fluorescence of the 2',7'dichlorofluorescein (DCFDA) and dihydroethidium (DHE) dye, respectively, were monitored by flow cytometry. No significant difference in both the $\mathrm{H}_{2} \mathrm{O}_{2}$ and superoxide concentration was observed in cells treated with Compound $\mathrm{C}$ (at concentrations up to $100 \mu \mathrm{M}$ ) compared with untreated cells (data not shown). Taken together, the results suggest that Compound $\mathrm{C}$ mediated inhibition of hypoxia dependent HIF- $1 \alpha$ stabilization is not due to inhibition of complex III derived ROS as previously suggested [1] but likely due to an effect on mitochondrial oxygen consumption.

\section{Conclusions}

The aim of this study was to determine the mechanism through which Compound $\mathrm{C}$ inhibits the stabilization of the HIF-1 $\alpha$ protein in hypoxia. We provide evidence that Compound $\mathrm{C}$ acts as a complex I inhibitor that affects the stabilization of the HIF-1 $\alpha$ protein independently of ROS production. Our results suggest that Compound C, like other mitochondrial ETC inhibitors, regulates HIF-1 $\alpha$ stability by controlling the cellular oxygen concentration leading to increased cellular oxygen availability and reactivation of prolyl hydroxylases in hypoxia $[5,7]$.

\section{Acknowledgements}

The study was supported by grant, R-183-001-216-112, from the Academic Research Fund.

\section{Authors' contributions}

$Y L$ carried out the experimental work and drafted the manuscript while $\mathrm{TH}$ participated in the design of the study, in evaluation of the results, in drafting and finalizing the manuscript. The authors have read and approved the final manuscript.

\section{Competing interests}

The authors declare that they have no competing interests.

Received: 28 December 2010 Accepted: 12 April 2011

Published: 12 April 2011

\section{References}

1. Emerling BM, Viollet B, Tormos KV, Chandel NS: Compound C inhibits hypoxic activation of HIF-1 independent of AMPK. FEBS Lett 2007, 581:5727-5731.

2. Brunelle JK, Bell EL, Quesada NM, Vercauteren K, Tiranti V, Zeviani M, Scarpulla RC, Chandel NS: Oxygen sensing requires mitochondrial ROS but not oxidative phosphorylation. Cell Metab 2005, 6:409-414.

3. Guzy RD, Hoyos B, Robin E, Chen H, Liu L, Mansfield KD, Simon MC, Hammerling U, Schumacker PT: Mitochondrial complex III is required for hypoxia-induced ROS production and cellular oxygen sensing. Cell Metab 2005, 6:401-408

4. Mansfield KD, Guzy RD, Pan Y, Young RM, Cash TP, Schumacker PT, Simon MC: Mitochondrial dysfunctional resulting from loss of cytochrome c impairs cellular oxygen sensing and hypoxic HIF-alpha activation. Cell Metab 2005, 6:393-399.

5. Chua YL, Dufour E, Dassa EP, Rustin P, Jacobs HT, Taylor CT, Hagen T: Stabilization of HIF-1alpha protein in hypoxia occurs independently of mitochondrial reactive oxygen species production. J Biol Chem 2010, 285:31277-31284.

6. Boveris A, Chance B: The mitochondrial generation of hydrogen peroxide. General properties and effect of hyperbaric oxygen. Biochem J 1973, 134:707-716.

7. Hagen T, Taylor CT, Lam F, Moncada S: Redistribution of intracellular oxygen in hypoxia by nitric oxide: effect on HIF 1 alpha. Science 2003, 302:975-978.

8. Chua YS, Chua YL, Hagen T: Structure Activity Analysis of 2Methoxyestradiol Analogues Reveals Targeting of Microtubules as the Major Mechanism of Antiproliferative and Proapoptotic Activity. Mol Cancer Ther 2010, 9:224-235.

doi:10.1186/1756-0500-4-117

Cite this article as: Chua and Hagen: Compound C prevents HypoxiaInducible Factor-1 $\alpha$ protein stabilization by regulating the cellular oxygen availability via interaction with Mitochondrial Complex I. BMC Research Notes 2011 4:117.

\section{Submit your next manuscript to BioMed Central and take full advantage of:}

- Convenient online submission

- Thorough peer review

- No space constraints or color figure charges

- Immediate publication on acceptance

- Inclusion in PubMed, CAS, Scopus and Google Scholar

- Research which is freely available for redistribution 